\title{
Achievement motives and emotional processes in children during problem-solving: Two experimental studies of their relation to performance in different achievement goal conditions
}

\author{
Gunnar Bjørnebekk • Torgrim Gjesme • \\ Robin Ulriksen
}

Published online: 20 May 2011

(C) The Author(s) 2011. This article is published with open access at Springerlink.com

\begin{abstract}
In two studies, the influence of key emotional and motivational factors on performance in different achievement goal-type situations is examined. In study 1, based on 314 sixth-graders, two types of goal situations were induced; performance and mastery. The goals were examined with respect to important antecedents (e.g., motive dispositions) and several consequences (e.g., performance, satisfaction, pleasant affect, worry, and emotionality). The results showed that the motive to achieve success $\left(M_{\mathrm{s}}\right)$ produced positive affects, satisfaction, and increased performance, whereas the motive to avoid failure $\left(M_{\mathrm{f}}\right)$ produced worries and performance reduction. In study 2 , based on 331 sixth-graders, three types of goal situations were induced; performance-approach, performanceavoidance, and mastery goals. The findings revealed that the most important single factors positively related to performance were $M_{\mathrm{s}}$ and mastery-goal situation. In addition, high $M_{\mathrm{s}}$ pupils performed better under mastery condition than under performance condition. Finally, avoidance-goal situation accentuate the negative effects of high $M_{\mathrm{f}}$ on performance.
\end{abstract}

Keywords Achievement goals - Motivation · Emotional processes $\cdot$ Performance $\cdot$ Achievement motives

\footnotetext{
G. Bjørnebekk ( $₫)$

The Norwegian Center for Child Behavioral Development, Postboks 7053 Majorstuen, 0306 Oslo, Norway

e-mail: gunnar.bjornebekk@atferdssenteret.no

T. Gjesme $\cdot$ R. Ulriksen

Institute for Educational Research, University of Oslo, Oslo, Norway
}

\section{Introduction}

Investigating potential person $\times$ situation interactions is essential if one is to make reasonable suggestions to teachers regarding the creation of an optimal achievement climate. Two major constructs in contemporary research on achievement motivation are achievement goals and achievement motives. In Elliot's hierarchal model (1999) motives and achievement goals are viewed as working together to regulate achievement behavior. Achievement motives include the motive to approach success $\left(M_{\mathrm{s}}\right)$ and the motive to avoid failure $\left(M_{\mathrm{f}}\right)$. All individuals are assumed to have both motives, but their strength differs according to the individual. The motives are defined as capacities to anticipate pleasure or pain, respectively, in achievement situations. A classroom setting represents an important area for display of achievement-related activities, which cannot be developed in a motivational vacuum. Further, it is obvious that any situation which represents a challenge to achieving success also poses the threat of failure. Accordingly, in a classroom setting achievement motives could play an important role in pupil performance and in activation of emotional processes related to approach and avoidance motivation. The effect of motives has, however, been shown to vary depending on the features of the current situation (e.g., Nygård 1975). Earlier studies suggest that achievement goal focus may be one of these features (Barron and Harackiewicz 2001; Harackiewicz and Elliot 1993).

There are assumed to be two primary goals or reasons determining why individuals engage in achievement behavior. A mastery goal orientation reflects a focus on developing competence and improving skills whereas a performance goal orientation reflects a focus on demonstrating competence (Linnenbrink 2004). According to achievement goal theory, goal orientations provide a 
framework for interpreting and reacting to events (Dweck and Leggett 1988). The orientations are presumed to differ as a function of situational demands (Maehr 1984), and their consequences are presumed to vary across individuals. For example, the results from Elliot and Harackiewicz's studies $(1994,1996)$ indicate that performance focus leads to enhanced intrinsic motivation in achievement-oriented individuals (e.g., high in $M_{\mathrm{s}}$ ), whereas individuals low in achievement orientation display the highest levels of intrinsic motivation when provided with mastery-focused goals. The principal idea behind the current study is that the disposition effects on motivational outcomes such as performance, satisfaction during problem-solving and state test anxiety appear both to occur directly and to be moderated by contextual-based goals. More precisely, our primary purpose is to probe motives as forerunners of different kinds of motivations during problem-solving and performance in different types of achievement goal conditions. Second, we wish to examine the role of worry and satisfaction during problem-solving in mediating the relation between motives and level of performance. We will also examine the main effects of achievement goal conditions. In the following paragraphs, the two major motivational constructs are presented first and then their main effects on motivational outcomes. This is followed by discussion on how individual differences can lead to different outcomes in performance and mastery goal contexts.

The relations between achievement motives, affects and performance during problem-solving

McClelland defined motive as "a strong affective association, characterized by an anticipatory goal reaction, and based on past association of certain cues with pleasure and pain" (1955, p. 226). The affectively charged anticipatory state energizes either approach processes (when positive affect is anticipated) or avoidance processes (when negative affect is anticipated). The motive to achieve success $\left(M_{\mathrm{s}}\right)$ refers to the capacity to anticipate pleasant affective changes occurring in performance situations perceived as challenging. Conversely, the motive to avoid failure $\left(M_{\mathrm{f}}\right)$ refers to the capacity to anticipate unpleasant affective changes occurring in performance situations where there is some uncertainty concerning the outcome (Gjesme and Nygård 1970). All individuals are assumed to have both a motive to achieve success $\left(M_{\mathrm{s}}\right)$ and a motive to avoid failure $\left(M_{\mathrm{f}}\right)$, but the strength of the achievement motives differs from one individual to another (Atkinson 1957). The anticipation of failure as a possible outcome in an achievement task arouses the latent motive to avoid failure $\left(M_{\mathrm{f}}\right)$. The anticipation of success arouses the latent need for achievement or the motive to achieve success $\left(M_{\mathrm{s}}\right)$.
This implies that in achievement situations two motivational tendencies are situationally aroused: the tendency to strive for success $\left(T_{\mathrm{s}}\right)$ and the tendency to avoid failure $\left(T_{\mathrm{f}}\right) . T_{\mathrm{s}}$ is an approach tendency that instigates actions directed at achieving success and is thought to be related to satisfaction and activated pleasant affect during problemsolving (Atkinson 1964; Bjørnebekk and Gjesme 2009). $T_{\mathrm{f}}$ is an avoidance tendency which directs the individual's behavior away from the achievement task and the possibility of failure and is thought to be related to state test anxiety (Elliot and McGregor 1999). When the task appears to the person to be either extremely difficult or very easy, that is, when the probability of success $\left(P_{\mathrm{s}}\right)$ is either very high or very low, neither the motive to achieve success $\left(M_{\mathrm{s}}\right)$ nor the motive to avoid failure $\left(M_{\mathrm{f}}\right)$ is strongly aroused. When the probability of success is intermediate, both achievement motives are strongly aroused and differences in strength of motives are maximized (Gjesme 1983a, p. 146). Thus, a pupil may very well have a strong motive to approach success without being motivated for school work, i.e., without having his/ her motives aroused in the school situation. This is likely to be the case if the probability of success is very high or very low (Atkinson 1964), the psychological distance to goal in time is long (Bjørnebekk 2009a; Gjesme 1974), or the perceived instrumentality of the activity is low (Raynor 1974). Thus, it is important to distinguish between motive and motivation, the first referring to a personality characteristic which may or may not manifest itself in a particular situation, and the second to its manifestation in a specific situation. Several empirical studies have shown that achievement motives are of significance in relation to performance and satisfaction at school or during problemsolving. The motive to approach success is positively related to performance (Atkinson and Litwin 1960; Bjørnebekk 2009a) and satisfaction and approach motivation $\left(T_{\mathrm{s}}\right)$ during problem-solving (Bjørnebekk and Gjesme 2009; Gjesme 1983a). Conversely, the motive to avoid failure is negatively related to performance (Bjørnebekk 2009a; Cock and Halvari 2001) and task well-being (Bjørnebekk 2009a; Gjesme 1983a).

Achievement goal focus as predictor and moderator of the motivation-performance relation

Teachers commonly use goals as a strategy to motivate their pupils in the classroom. The type of academic goal pursued by students is also considered one of the most important variables in motivational research in educational contexts (Bjørnebekk 2008b; Elliot 1999). It is possible that, more than any other research program, research on achievement goals has been conducted with an eye toward classroom application (Urdan and Turner 
2005, p. 298). Differently from action-state orientation, which reflects a goal striving approach to motivation (Kuhl 1994), achievement goals reflect social cognitions about the purpose and reasons for achievement and the type of standard by which individuals can judge their performance in reaching that goal (Pintrich 2000). The personal achievement goals that pupils adopt in the classroom are believed to be influenced by the goal message that is made apparent in the achievement context (Ames 1992). There may be many different goal orientations, but the two that are always represented in the theories are labeled mastery and performance goals (Ames and Archer 1988). The first group encompasses individuals who exhibit their own abilities and try to perform better-or at least no worse-than others. The goals of the individuals in this group are called performance goals (Elliott and Dweck 1988) or ability-focused goals (Maehr and Midgley 1991). The second group encompasses individuals who look upon learning as an objective in itself and seek to improve personal achievement. The goals of the individuals in this group are called mastery goals (Elliot and Harackiewicz 1996) or learning goals (Dweck and Leggett 1988). Researchers in achievement goal theory generally associate performance goals with a number of negative processes and consequences. For example, it is assumed that a person who has set a performance goal will give up more easily in the face of difficulty (Dweck 1986). It is also assumed that performance goals are linked to decreased motivation (Nicholls 1989) as well as to a tendency to use strategies that promote surface processing of the material, such as rehearsal strategies (Nolan 1988). Mastery goals, on the other hand, are seen as linked to a number of positive processes and consequences. It is assumed that a person who has set a mastery goal will show considerable perseverance in encountering opposition (Dweck and Leggett 1988), will seek out optimal challenges (Dweck 1986), will tend to use strategies that promote deeper processing of the material (Ames 1984), and will become intrinsically motivated (Elliot and Harackiewicz 1996). Owing to inconsistent evidence about the relations among performance goal orientation, activation of approach motivation, and performance outcomes, however, a trichotomous model, which differentiates between performance approach, performance avoidance, and mastery goal orientation was proposed (Elliot 1997). Each of the three achievement goals has been shown to be related to emotional processes during problem-solving and performance. According to Tyson, Linnenbrink-Garcia and Hill's recent review (2009) adoption of performance-avoidance goals is associated with lower achievement and outcomes related to activation of avoidance motivation. Furthermore, $40 \%$ of the correlations showed a positive correlation between adoption of mastery goals and achievement and between adoption of a performance-approach goal and achievement. Only adoption of mastery goals, however, seems to be consistently associated with emotional processes related to activation of approach motivation. More recently, a $2 \times 2$ framework grounded in both the mastery-performance distinction and the distinction between approach goals and avoidance goals has been considered (Bjørnebekk and Diseth 2010; Elliot and McGregor 2001). The mastery avoidance goal was not included in the present research because it was presumed to be less relevant to the age group under consideration.

Much of this previous work, however, has focused on students' personal goal orientations (e.g., Dweck 1986) or students' perceptions of the contexts (e.g., Roeser et al. 1996). Experimental manipulation of the classroom goal structure provides the greatest insight into how changes to the learning context can alter pupils' performance and affects during problem-solving. Research using experimental manipulation of classroom goals and their results is however limited (e.g., Linnenbrink 2004).

According to Atkinson's theory (1964), activation of achievement motives depends on the strength of the motives and the probabilities of success. Both the performance focus and the mastery focus make competence salient and thereby facilitate the activation of the motives. Achievement goals reflect normative standards for performance (e.g., performance goals) or are based on task characteristics and personal improvement (e.g., mastery goals), and these foci may activate the motive to achieve success and the motive to avoid failure differently. According to Dweck (1986), performance goals can evoke evaluation anxiety (e.g., state test anxiety) and disrupt task involvement, whereas mastery goals may promote task involvement (e.g., satisfaction during problem-solving) because they highlight self-referential evaluation and ongoing improvement. Considering these effects together, and because pupils high in $M_{\mathrm{f}}$ characteristically avoid normative comparison and are likely to experience performance anxiety in achievement settings (Atkinson 1964), the high $M_{\mathrm{f}}$-group should be more performanceoriented.

Also, recent studies have tested out the hypothesis that the motivational outcome of achievement goals can be differentiated according to individual differences in motivation-related dispositions. Earlier experiments on intrinsic motivation indicate that individuals low in the motive to achieve success $\left(M_{\mathrm{s}}\right)$ respond most positively to assigned mastery focus (Durik and Harackiewicz 2003; Elliot and Harackiewicz 1994; Harackiewicz and Elliot 1993), whereas performance goals prove optimal for those high in the motive to achieve success (Elliot and Harackiewicz 1994), or those high in the motive to achieve success who 
enjoy solving tasks regardless of goal focus (Durik and Harackiewicz 2003). The motive to avoid failure was not included in these studies.

A clear understanding of the effects of goal climates on motivational outcomes such as performance and affects during problem-solving may require investigation of motives as moderators of the effects of classroom goals. Surprisingly, it appears that no published study has examined the relationship between achievement motives and motivational outcomes such as performance and affects during problem-solving in children under different goal conditions. In earlier experiments which investigated the interactive effects of the motive to achieve success and evaluative focus of assigned task-specific goals on intrinsic motivation, the participants were undergraduates enrolled in introductorylevel psychology courses (e.g., Elliot and Harackiewicz 1994). If the relationship between individual differences in motives and assigned goal-focus could be measured in a youth population, it would be a valuable addition to the existing literature and could promote further research on the development of such relationships in school settings.

Affective experiences during problem-solving mediating the relation between achievement motives or achievement goals and the level of performance

State test anxiety consists of two distinct components; worry reflecting cognitive reactions to a performance situation (e.g., concern over performance), and emotionality, reflecting physiological and affective reactions (e.g., accelerated heart rate). Research has revealed that worry undermines performance in testing situations, whereas emotionality does not (Brodish and Devine 2009; Elliot and McGregor 1999; Gjesme 1983b). The motive to avoid failure represents a dispositional tendency to experience negative affects and cognitions during performance situations (e.g., worries and unpleasant affects). According to Elliot's (2006) and Elliot and McGregor's (1999) hierarchical model of approach-avoidance motivation, the motive to avoid failure gives rise to avoidance goals and worry is posited as the mechanism responsible for the deleterious influence of avoidance goals on performance (Elliot 2006; Elliot and McGregor 1999). Bjørnebekk's (2009a) study indicates, however, that for children the motive to avoid failure directly influences performance and task well-being during problem-solving and is not mediated by performance-avoidance goals. A recent study by Bjørnebekk and Gjesme (2009) substantiated a partial mediation process caused by avoidance motivation $\left(T_{\mathrm{f}}\right)$ on the negative relationship between the motive to avoid failure and performance.
On the other hand, once the motive to achieve success is activated; it energizes the individual, ultimately making him or her aware of the possibility of success. Therefore, the motive to achieve success is assumed to be positively related to positive cognitions and mood states during problem-solving (e.g., satisfaction during problem-solving or/and pleasant affects). The hierarchical model further proposes that the effect of the motive to achieve success on performance is mediated by performance approach goals and the relationship between the motive to achieve success and satisfaction during problem-solving is mediated by mastery-approach goals (Elliot 1997; Elliot and Church 1997). In Bjørnebekk (2009a), the assumed mediation on the relationship between the motive to achieve success and performance was not independently substantiated since achievement goals did not predict performance, while controlling for scores on the motives. In the latter study, however, a model with mastery-approach goal adoption mediating the relationship between the motive to achieve success and task well-being was supported. In Bjørnebekk and Gjesme (2009), an approach motivation mediational analysis failed to yield a significant relationship between approach motivation and performance; therefore, approach motivation failed to satisfy the third requirement for mediation between the motive to achieve success and performance. In Puca and Schmalt's study (1999), the relationship between achievement motives $\left(M_{\mathrm{s}}-M_{\mathrm{f}}\right)$ and performance was mediated by task enjoyment. Unfortunately, in this study as well the participants were university students. The motive to avoid failure is assumed to dampen the positive motivation and increase avoidance motivation (e.g., state test anxiety) and the motive to approach success is assumed to increase positive motivation and the tendency to undertake an activity. This conception combined with the assumption that performance level is a function of motivational strength implies that there should be a positive relationship between the strength of the motive to achieve success and performance level, and a negative relationship between the strength of the motive to avoid failure and performance level (see, for example, Nygård 1975). Furthermore, it implies that worry might account for the relationship between the motive to avoid failure and performance and satisfaction/activated positive affect during problem-solving for the relationship between the motive to approach success and performance.

We have decided not to posit any hypotheses although we do have some presentiments as to what the data analysis will reveal. Likewise, no specific hypotheses are presented for gender differences. 


\section{Study 1}

\section{Method}

\section{Participants}

The sample consisted of 314 sixth-graders (11-12-yearolds) from 18 school classes in Oslo. The classes were selected from schools which scored on the same level in the Norwegian national test in mathematics and reading. In terms of composition, the sample consisted of 164 boys and 150 girls. Fifteen percent of the pupils in the schools where the classes were recruited had Norwegian as their second language. Most of the pupils with a non-Norwegian background were from Asia (mainly Pakistan). The average mathematics and reading scores for the schools in the sample were 55 and 59, respectively. The average scores in Oslo schools were 53 and 54, respectively. The raw scores were converted to standardized $\mathrm{T}$-scores on a national basis: $M=50$ and $\mathrm{SD}=10$. As we can see, important characteristics of the participants in the present study were that the majority had Norwegian as their first language and as a group they scored above average on the nationwide tests. Data collection was conducted by the third author and a graduate student research assistant. After securing the principal's permission, they contacted the selected classes' primary teacher and the parents' council working committee. Pupils were told that their participation in the study was voluntary and they were free to withdraw at any time and were assured of confidentiality. Only two pupils refused to participate in the study. No remuneration or other incentive was offered, and the pupils were not required to provide their name or any identifying information. Participation in the study was therefore anonymous and voluntary.

\section{Assessment of variables}

Motives The achievement motives scale (AMS) (Gjesme and Nygård 1970) is used to assess achievement motives. The AMS is based on achievement motivation theory and consists of (a) items referring to both positive and negative affects and (b) items focusing on situations that supposedly arouse a similar degree of uncertainty as to the possibility of success. To illustrate, the following item is intended to measure $M_{\mathrm{s}}$ : "I feel pleasure at working on tasks that are fairly difficult for me," whereas the following item is meant to measure $M_{\mathrm{f}}$ : "I become anxious when I meet a problem I don't understand at once." The AMS consists of 30 statements about the affect experienced in connection with achievement situations which are rated on a scale from one (not at all true of me) to four (very true of me). Results regarding the reliability and validity of the scale as applied to elementary school pupils were summarized by Christophersen and Rand (1982). The scale has also been examined and given a positive evaluation by several researchers and has been described as well-tuned to the motive concept within achievement motivation theory (e.g., Bjørnebekk 2009b; Halvari 1997; Kuhl 1982; Thrash et al. 2007).

Pleasant affects This scale was constructed using the terms from the schematic model presented by Yik et al. (1999) as guidelines. Three core affect items for every eight octants were collected systematically to sample and cover each region of the circular structure of the affect. In this study, we only used the pleasant affect scales. The pleasant affect factor consisted of the octants "pleasantness," "pleasant deactivation," and "pleasant activation." All items are in state form and relate to the problem-solving situation. The pleasant affect factor comprises nine specific core affect-related adjectives, rated on a five-point scale from "very slightly/not at all" to "very much." The adjectives are "inspired," "relief," "enthusiastic,"”happy," "contented," "excited," "engaged," "interested," and "delighted." In the instructions for the scales in the study, participants were asked to indicate "to what extent did you feel this way during the problem-solving session?" The scales have been successfully used in previous research on Norwegian elementary school pupils (Bjørnebekk 2007, 2009a). In the present study, a principal factor analysis showed that only one factor had eigenvalues greater than one (the first two eigenvalues were, respectively, 4.37 and 0.88 ). All items loaded satisfactorily on the pleasant affects factor (i.e. $>40$ ). The factor accounted for $49 \%$ of the total variance. Reliability for the scale was 0.86 .

Satisfaction during problem-solving (SDPS) This scale is a five-item state version that measures overall satisfaction with the experience of taking part in a problem-solving session with a version of Updegraff, Gable, and Taylor's end-of-study satisfaction scale (2004). SDPS measures the cognitive judgmental aspect of task well-being (e.g., "Looking back, the last half hour has been fine"). Responses were rated on a scale from one (is not at all true of me) to four (is very true of me). Bjørnebekk's (2007, 2009a) empirical studies documented the reliability and validity of using this measure for Norwegian elementary school children. In the present study, a principal factor analysis showed as expected that only one factor had eigenvalues greater than one. All items loaded satisfactorily on the SPDS factor (i.e., >40). The factor accounted for $59 \%$ of the total variance. Reliability for the scale was 0.85 .

State test anxiety measure (STA) Six worry and six emotionality items were employed. The worry items dealt with worry about the tasks, cognitive concern about failing, 
and negative self-evaluation experienced during problemsolving sessions (e.g., "I worried about getting too many answers wrong while I was solving the problems"). The emotionality items concerned attention directed toward cues of physiological arousal, such as heart racing, upset stomach, and trembling in connection with the problemsolving session (e.g., "Once in a while my heart pounded hard while I was solving the problems"). In the instructions for the scales in the study, participants were asked: "How did you feel while you were solving the problems?" The items were taken from the Norwegian translations of the STAIC A-State scale (Spielberger 1973) and the Test Anxiety Scale for Children (TASC; Sarason et al. 1958) and were constructed to measure worry (W) and emotionality (E) during problem-solving sessions. Bjørnebekk's (2008a) and Gjesme's (1983b) empirical studies have documented the reliability and validity of using this measure for Norwegian elementary school children. In the present sample, a principal factor analysis with oblimin rotation showed that two factors had eigenvalues greater than one (the first three eigenvalues were, respectively, $5.99,1.25$, and 0.92 ). The two-factor solution accounted for $64 \%$ of the total variance. All items loaded satisfactorily on their primary factor (i.e. >40). The emotionality item, however, "My body and legs became restless when I was faced with problems that were difficult for me to solve" also loaded substantially (in the pattern matrix) on the worry factor $(0.41)$.

Tasks There were three different types of verbal problems and four different types of numerical problems. The first set of verbal problems were anagrams of four to seven letters that were to be put together to make nouns. Second were verbal analogies with one pair of related words and another unpaired word. The pupils were asked to choose one word from among four that had the same relation to the unpaired word as the first pair of words. Third, six words were presented, one of which was the antonym of a word written in capital letters. The pupils were asked to underline the antonym.

With regard to the numerical problems, first, nine or ten two-, three- and four-digit numbers were spread out within a square in which the students were asked to draw a ring around the number that was twice as great as another number in the square. Second, two lines of numbers were presented, and students were asked to draw a ring around the number on the second line that could be subtracted from a number in the first line to achieve the sum of 25 . Third, eight numbers were presented, of which two were to be added together to achieve the sum of 1,000. The pupils were instructed to draw rings around those two numbers. The fourth problem consisted of four numbers that were to be added together in each task square. There were two reasons for using two types of problems: (1) girls perform better in perceptual speed and some verbal tasks, whereas boys outperform girls in mental rotation and some mathematical tasks (Hyde 2005) and (2) the effect of numerical problems on failure-oriented pupils.

Earlier studies have revealed that the tasks were described as intermediately challenging in a difficulty estimate given by 580 sixth-graders immediately after the completion of each of these seven tasks. A five-point scale was employed: "Very hard" (5), "Hard" (4), "Medium" (3), "Easy" (2), and "Very easy" (1). The rating was done after the completion of each task; it is therefore not necessarily representative of the difficulty impression (the probability of success; $P_{\mathrm{s}}$ ) which was effective during work on the task. The ratings were, however, based on very recent experience with the tasks and probably represent $P_{\mathrm{s}}$ indications of some validity (Bjørnebekk and Gjesme 2009).

\section{Experimental procedure}

The experiment was carried out in a group-testing session.

Procedure The 18 school classes were randomly assigned to two different experimental conditions, mastery goal, and performance goal. Before the experimental procedures were induced, the pupils' motive dispositions were assessed. Each class received the instructions for the condition it was assigned to. Then, pupils received a booklet of problem tasks. The pupils in the two conditions received a test booklet containing identical sets of tasks (41 problems). After the pupils had received the booklets, and after examples of all types of tasks had been illustrated, the specific instruction for the two experimental achievement goal conditions followed:

Performance goal condition "The problems you have the opportunity to answer today were constructed in a way which will allow you to compare your results with others. What we are interested in is how well you perform on the tasks as compared with other sixth-graders. When you have finished, you will have the opportunity to know how well you performed compared with others."

Mastery goal condition "The problems you have the opportunity to answer today were constructed in a way which will allow you to discover new ways and strategies to solve them if you are working carefully on them. What we are interested in is how much you improve your skills by working with this type of problem. When you have finished, you will have the opportunity to learn whether you did well and made progress toward mastering these tasks." 
Under both conditions, the pupils were given 20 min to work with the booklet. After the participants performed the anagram problems, they were asked to indicate the purpose of the task (as a manipulation check) and to fill out scales indicating state test anxiety, satisfaction, and pleasant affect during problem-solving. Coding of subjects' openended responses revealed that nearly all participants correctly stated the purpose of the experiment and suggests that the experimental manipulations worked.

Treatment of data We conducted multilevel analyses, using the SPSS version 15.0 linear mixed model program to analyze the data, with sex, motives, the achievement conditions, and their interactions at level 1 and classes at level 2. First, we conducted preliminary analyses in which we proportioned the total variance of the dependent variables into within-classes and between-classes components (model 0). The intraclass correlation for each variable was estimated by dividing the variance associated with the intercept by the sum of the residual variance plus the variance associated with the intercept (Singer and Willett 2003). Second, we tested the significance of each of the random components using restricted maximum likelihood (REML) estimation (Raudenbush and Bryk 2002). Third, after non-significant random error terms were dropped from the model, we examined our hypotheses with multilevel regression analyses for each of the dependent variables. The achievement goal conditions were dummy coded by zero (performance goal condition) and one (mastery goal condition), and sex by zero representing boys and one representing girls, respectively. All interaction product terms were constructed using mean-deviated main effects. Significant interaction effects were interpreted by generating predicted values from the regression equations using scores of one standard deviation above (high) and below (low) the mean for the continuous variables (Aiken and West 1991). Multilevel analyses were also used to test potential mediation (Krull and MacKinnon 2001) by performing a Sobel's test (1982). Descriptive statistics, reliabilities and correlations at the within-class level among the variables are presented in Table 1 .

The intraclass correlations (ICC) were evaluated for our dependent variables (e.g., satisfaction, pleasant affect, worry, emotionality, and total performance) by dividing the variance associated with the intercept by the sum of the residual variance plus the variance associated with the intercept (Singer and Willett 2003). The ICCs were weak and ranged from 0.01 (emotionality) to 0.15 (satisfaction), indicating that most of the variance was at the individual level. ICC values were significant in one out of five cases (satisfaction). For the other four cases, multilevel regression was used for consistency and because it best represented the structure of the data. The slopes of the motive to achieve success and the motive to avoid failure did not evidence significant variation among classes, so the motive effects were treated as fixed in the final model. The low correlation between $M_{\mathrm{s}}, M_{\mathrm{f}}$, the achievement goal condition, and sex (ranging from 0.02 to 0.12 ) suggest that multicollinearity is not a concern in analyses in which these variables are evaluated simultaneously. Each two-way interaction was tested separately, however, because of concerns about multicollinearity (i.e., $M_{\mathrm{s}} \times M_{\mathrm{f}}, M_{\mathrm{s}} \times$ AGC, $M_{\mathrm{s}} \times \operatorname{sex}, M_{\mathrm{f}} \times \operatorname{sex}, M_{\mathrm{f}} \times$ AGC, AGC $\left.\times \operatorname{sex}\right)$. The usual requirement for developing a regression equation that includes a three-way interaction is that all the first- and second-order terms must be included in the equation (Aiken and West 1991). To avoid the data being stretched too thinly, an approach-avoidance interaction model (i.e., $M_{\mathrm{s}} \times \mathrm{AGC}, M_{\mathrm{f}} \times \mathrm{AGC}, M_{\mathrm{s}} \times M_{\mathrm{f}}$, and $\left.M_{\mathrm{s}} \times M_{\mathrm{f}} \times \mathrm{AGC}\right)$, an avoidance-sex interaction model (i.e., $\mathrm{Sex} \times \mathrm{AGC}$, $M_{\mathrm{f}} \times \operatorname{sex}, \mathrm{AGC} \times M_{\mathrm{f}}$, and $\left.M_{\mathrm{f}} \times \operatorname{sex} \times \mathrm{AGC}\right)$, and an approach-sex interaction model (i.e., Sex $\times$ AGC, $M_{\mathrm{s}} \times \mathrm{Sex}, \mathrm{AGC} \times M_{\mathrm{s}}$, and $M_{\mathrm{s}} \times \operatorname{sex} \times \mathrm{AGC}$ ) were tested separately. When a three-way interaction was significant, we included all of the variables in the model in the equation. Thus, in the first model, the dependent variables

Table 1 Descriptive statistics, reliabilities, and intercorrelations among the variables in study 1

\begin{tabular}{|c|c|c|c|c|c|c|c|c|c|c|c|c|}
\hline$N=314$ & M & $\mathrm{SD}$ & $\alpha$ & 1 & 2 & 3 & 4 & 5 & 6 & 7 & 8 & 9 \\
\hline 1. Gender & - & - & - & 1 & & & & & & & & \\
\hline 2. Motive to achieve success & 39.8 & 9.1 & 0.90 & $0.12 *$ & 1 & & & & & & & \\
\hline 3. Motive to avoid failure & 28.3 & 8.5 & 0.88 & 0.02 & -0.09 & 1 & & & & & & \\
\hline 4. Achievement goal condition & - & - & - & 0.02 & 0.10 & 0.06 & 1 & & & & & \\
\hline 5. Worry & 10.7 & 4.2 & 0.87 & $0.15 * *$ & 0.10 & $0.27 * *$ & -0.04 & 1 & & & & \\
\hline 6. Emotionality & 9.1 & 3.6 & 0.85 & 0.06 & 0.02 & 0.06 & -0.09 & $0.69 * *$ & 1 & & & \\
\hline 7. Pleasant affect & 26.1 & 7.4 & 0.86 & -0.00 & $0.39 * *$ & -0.05 & 0.09 & 0.06 & 0.09 & 1 & & \\
\hline 8. Satisfaction & 13.0 & 3.9 & 0.85 & 0.08 & $0.34 * *$ & -0.10 & $0.19 * *$ & 0.05 & 0.04 & $0.63 * *$ & 1 & \\
\hline 9. Performance & 19.7 & 8.4 & 0.91 & 0.00 & $0.33 * *$ & $-0.26^{* *}$ & -0.03 & $-0.19 * *$ & $-0.11 *$ & $0.16 * *$ & 0.01 & 1 \\
\hline
\end{tabular}

$* p<0.05 ; * * p<0.01$ (two-tailed) 
were regressed on $M_{\mathrm{s}}, M_{\mathrm{f}}$, sex, and the achievement goal conditions. In the next model, the two-way interactions were included. In the last model, the three-way interactions were added. In all models, classes were included as a level 2 variable. Any effects not reported were non-significant.

Results

As seen from Table 1, there were some significant correlations between $M_{\mathrm{s}}$ and performance, positive affects, and satisfaction. The relationship between $M_{\mathrm{f}}$ and worry, as well as a negative relation between $M_{\mathrm{f}}$ and performance, was also significant. Moreover, the positive relationship between the achievement goal conditions and satisfaction was significant. Pupils in the mastery goal condition scored higher on satisfaction than pupils in the performance goal condition.

\section{Worry and emotionality}

Table 2 revealed the roles of gender, the motive to approach success, the motive to avoid failure, the achievement goal conditions, and their interactions in the prediction of worry and emotionality during the problemsolving session. The final moderated multilevel regression model accounted for $8.8 \%$ of the variance of worry. As shown in Table 2, gender positively predicted worry during problem-solving. The worries of girls were higher than the worries of boys during the problem-solving session $(B=112 ; p<0.05)$. The motive to achieve success $(B=0.05 ; p<0.05)$ and the motive to avoid failure ( $B=0.14 ; p<0.01)$ were also positively related to worry. The achievement goal conditions were shown to be

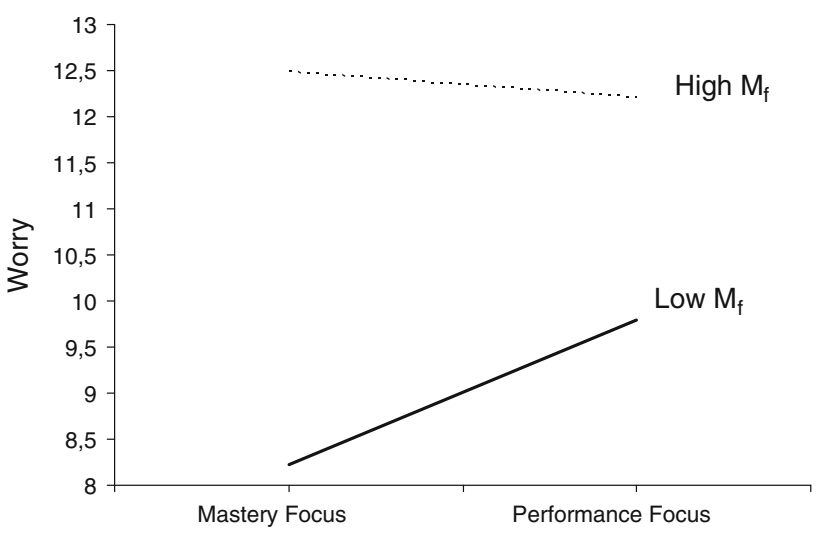

Fig. 1 Worry as a function of combinations of the motive to avoid failure $\left(M_{\mathrm{f}}\right)$ and the achievement goal conditions

unrelated to worry. As can be seen in model 2, however, there was a significant achievement goal condition $\times$ motive to avoid failure $\left(M_{\mathrm{f}}\right)$ interaction in the prediction of worry $(B=0.11 ; p<0.05)$. The interaction is graphically portrayed in Fig. 1. The worries of pupils low in the motive to avoid failure were higher under the performance goal condition than under the mastery goal condition.

The second multilevel regression model focused on the same relationships with one difference, i.e., the outcome variable was emotionality. None of the main variables were significantly related to emotionality during problem-solving. The effect of the achievement goal condition was however marginally significant $(B=-0.75 ; p<0.10)$, and the interaction between the motive to avoid failure and the achievement goal condition was significantly related to emotionality during problem-solving $(B=0.10 ; p<0.05)$.

Table 2 Multilevel regressions: Sex, motives, and achievement goal condition at level 1 and classes at level 2 as predictors of worry and emotionality during problem-solving

\begin{tabular}{|c|c|c|c|c|c|c|c|c|}
\hline \multirow[t]{3}{*}{ Fixed effects } & \multicolumn{4}{|l|}{ Worry } & \multicolumn{4}{|c|}{ Emotionality } \\
\hline & \multicolumn{2}{|l|}{ Model 1} & \multicolumn{2}{|l|}{ Model 2} & \multicolumn{2}{|l|}{ Model 1} & \multicolumn{2}{|l|}{ Model 2} \\
\hline & Coefficient & $\mathrm{t}$ & Coefficient & $\mathrm{t}$ & Coefficient & $\mathrm{t}$ & Coefficient & $\mathrm{t}$ \\
\hline Intercept & $10.45 * *$ & 25.81 & $10.42 * *$ & 25.88 & $9.30 * *$ & 24.88 & $9.28 * *$ & 24.26 \\
\hline Sex & $1.12 *$ & 2.44 & $1.09 *$ & 2.40 & 0.43 & 1.07 & 0.42 & 1.04 \\
\hline Motive to achieve success & $0.05 *$ & 2.05 & $0.05 *$ & 2.00 & 0.01 & 0.57 & 0.01 & 0.45 \\
\hline Motive to avoid failure & $0.14 * *$ & 5.24 & $0.09 *$ & 2.31 & 0.03 & 1.17 & 2.516 & \\
\hline Achievement goal condition & -0.61 & 1.32 & 0.60 & -1.30 & $-0.75^{\dagger}$ & -1.74 & $-1.33 *$ & -2.32 \\
\hline$M_{\mathrm{f}} \times$ Achievement goal & & & $0.11 *$ & 2.07 & & & $0.10 *$ & 1.97 \\
\hline Sex $\times$ Achievement goal & & & & & & & $1.26^{\dagger}$ & 1.56 \\
\hline$\Delta R^{2}$ & $7.8 \%$ & & $1 \%$ & & $0.5 \%$ & & $1.1 \%$ & \\
\hline $\mathrm{ICC}$ & $2 \%$ & & & & $1 \%$ & & & \\
\hline
\end{tabular}

$M_{s}$ Motive to achieve success, $M_{f}$ Motive to avoid failure

$* p<0.05 ; * * p<0.01$ (two-tailed); ${ }^{\dagger} p<0.10$ (one-tailed) 
Pupils in the performance goal condition had marginally significantly higher emotionality scores during the problem-solving session $(M=9.46, \quad \mathrm{SD}=4.06)$ than the pupils in the mastery goal condition $(M=8.79$, $\mathrm{SD}=3.12$ ). Moreover, the significant achievement goal condition $\times$ motive to avoid failure $\left(M_{\mathrm{f}}\right)$ interaction indicates that the scores on emotionality of pupils low in $M_{\mathrm{f}}$ increased from the mastery goal condition to the performance goal condition.

\section{Satisfaction and pleasant affects}

The third multilevel regression analysis focused on satisfaction during the problem-solving session and, as before, the variables were entered into the regression equation as described in Table 3. On this occasion, there were three significant predictors; the motive to achieve success $(B=0.12, p<0.01)$, the motive to avoid failure $(B=$ $-0.05, p<0.05)$, and the achievement goal condition $(B=1.55, p<0.05)$. Pupils in the mastery goal condition were more satisfied during the problem-solving session than were the pupils in the performance goal condition.

In the analogous multilevel regression analysis on pleasant affect, the model accounted for $14.1 \%$ of the variance. As evident in Table 3, the model yields one significant main effect: level of motive to achieve success showed a positive link to pleasant affect during problemsolving $(B=0.32, p<0.001)$. As can be seen, there was also a significant motive to avoid failure $x$ motive to achieve success interaction predicting level of pleasant affect $(B=-0.01, p<0.05)$. As depicted in Fig. 2, pupils scoring high on the motive to achieve success and low on

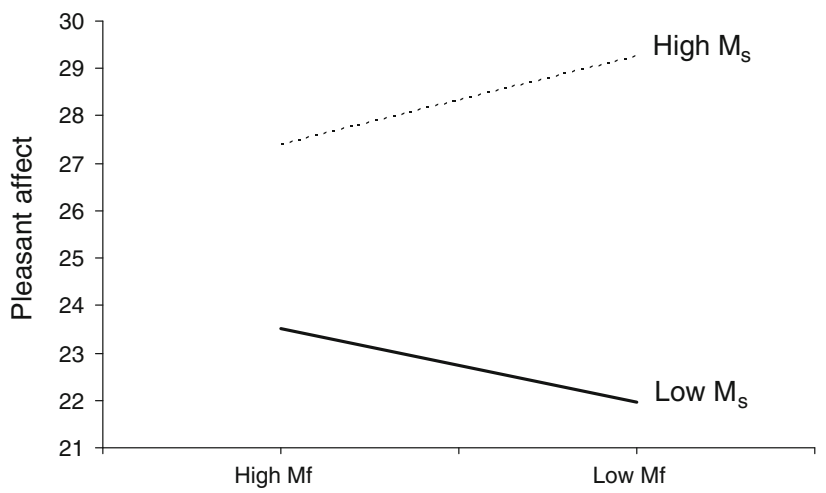

Fig. 2 Pleasant affect during problem-solving as a function of combinations of the motive to achieve success $\left(M_{\mathrm{s}}\right)$ and the motive to avoid failure $\left(M_{\mathrm{f}}\right)$

the motive to avoid failure had the highest scores on pleasant affect during problem-solving, whereas pupils scoring low on both motives had the lowest.

\section{Performance}

Regressing total performance on the proposed antecedents yielded a significant effect for the overall model. The final moderated hierarchical regression model accounted for $21 \%$ of the variance in total performance. As shown in Table 4 , the motive to achieve success emerged as a positive predictor of performance in step $1(B=0.35$, $p<0.01)$ and the motive to avoid failure as a negative $(B=-0.21, p<0.01)$. Neither the achievement goal condition nor the interactions were statistically significantly related to performance.

Table 3 Multilevel regressions: Sex, motives, and achievement goal condition at level 1 and classes at level 2 as predictors of satisfaction and pleasant affects during problem-solving

\begin{tabular}{|c|c|c|c|c|c|c|}
\hline \multirow[t]{3}{*}{ Fixed effects } & \multirow{2}{*}{\multicolumn{2}{|c|}{$\frac{\text { Satisfaction }}{\text { Model } 1}$}} & \multicolumn{4}{|c|}{ Pleasant affect } \\
\hline & & & \multicolumn{2}{|l|}{ Model 1} & \multicolumn{2}{|l|}{ Model 2} \\
\hline & Coefficient & $\mathrm{t}$ & Coefficient & $\mathrm{t}$ & Coefficient & $\mathrm{t}$ \\
\hline Intercept & $11.94 * *$ & 23.30 & $26.04 * *$ & 33.06 & $25.94 * *$ & 32.85 \\
\hline Sex & 0.27 & 0.67 & -0.77 & -0.99 & -0.86 & -1.11 \\
\hline Motive to achieve success & $0.12 * *$ & 5.04 & $0.32 * *$ & 7.18 & $0.31 * *$ & 6.99 \\
\hline Motive to avoid failure & $-0.05^{*}$ & -2.25 & -0.02 & -0.45 & -0.01 & -0.29 \\
\hline Achievement goal condition & $1.55^{*}$ & 2.33 & 0.70 & 0.73 & 0.84 & 0.87 \\
\hline$M_{\mathrm{f}} \times M_{\mathrm{s}}$ & & & & & $-0.01 *$ & -2.22 \\
\hline$\Delta R^{2}$ & $9 \%$ & & $12.6 \%$ & & $1.5 \%$ & \\
\hline ICC & $15 \%$ & & & $5 \%$ & & \\
\hline
\end{tabular}

$M_{s}$ Motive to achieve success, $M_{f}$ Motive to avoid failure

$* p<0.05 ; * * p<0.01$ (two-tailed) 
Table 4 Multilevel regressions: Sex, motives, and achievement goal condition at level 1 and classes at level 2 as predictors of performance

\begin{tabular}{|c|c|c|c|c|}
\hline \multirow[t]{3}{*}{ Fixed effects } & \multicolumn{4}{|c|}{ Performance } \\
\hline & \multicolumn{2}{|l|}{ Model 1} & \multicolumn{2}{|l|}{ Model 2} \\
\hline & Coefficient & $\mathrm{t}$ & Coefficient & $\mathrm{t}$ \\
\hline Intercept & $20.50 * *$ & 18.23 & $19.70 * *$ & 16.09 \\
\hline Sex & -0.51 & -0.60 & 1.24 & 0.96 \\
\hline Motive to achieve success & $0.35 * *$ & 7.03 & $0.34 * *$ & 6.85 \\
\hline Motive to avoid failure & $-0.21 * *$ & -4.20 & $-0.21 * *$ & -4.17 \\
\hline Achievement goal condition & -1.03 & -0.71 & 0.41 & 0.24 \\
\hline Sex $\times$ Achievement goal & & & $-3.07^{\dagger}$ & -1.79 \\
\hline$\Delta R^{2}$ & $20 \%$ & & $1 \%$ & \\
\hline ICC & $3 \%$ & & & \\
\hline
\end{tabular}

$M_{s}$ Motive to achieve success, $M_{f}$ Motive to avoid failure

$* p<0.05 ; * * p<0.01$ (two-tailed)

\section{Mediational analysis}

Multilevel mediation analyses were used to test the mediation models (Krull and MacKinnon 1999) with classes included as a level 2 variable in all models. The level 1 predictors were mean-centered. To reveal whether worry mediates the motive to avoid failure-performance linkage and pleasant affects/satisfaction during problem-solving mediate the motive to achieve success-performance linkage, several stages of analysis are necessary. First, the predictor-criterion correlation must be significant. The analysis satisfied this requirement by establishing a positive relationship between the motive to achieve success and performance $(B=0.37 ; p<0.01)$, as well as a negative relationship between the motive to avoid failure and performance $(B=-0.026 ; p<0.01)$. Second, a relationship between the predictor variable and the hypothesized mediator must be established to document the first link in the mediational chain. The relationships between the motive to approach success and satisfaction $(B=0.13$; $p<0.01)$ pleasant affect $(B=0.32 ; p<0.01)$ and between the motive to avoid failure and worry $(B=0.14$; $p<0.01)$ were significant. Third, to complete the mediational chain, a relationship between the mediator and the outcome variable must be established while controlling for the predictor variable and the direct relationship between the predictor variable and the outcome measure should be reduced. To test the final link, we conducted a series of analyses in which performance was also regressed on the motives with affects during problem-solving (i.e., worry, pleasant affect, and satisfaction) and classes (as a level 2 variable) in the equation. The mediational analyses failed to yield a significant relationship between satisfaction and performance and between pleasant affect and performance while controlling for scores on the motive to achieve success and classes; therefore, satisfaction and pleasant affect failed to satisfy the third requirement for mediation. In the avoidance mediational analyses, the relationship between worry and performance was still significant, while controlling for scores on the motive to avoid failure $(B=-0.24, p<0.05)$. The coefficient for the direct relationship between the motive to avoid failure and performance dropped from -0.26 to -0.22 in this analysis. The utilization of Sobel's procedure (1982) for testing the significance of indirect, mediational relationships substantiated only a partial mediation process of worry on the relationship between the motive to avoid failure and performance $(z=-1.99, p<0.05)$.

\section{Discussion}

The objective in this study was to shed light on the influence of key motivational variables on performance and satisfaction in two different goal-type conditions. This type of research seems particularly important for making recommendations to teachers because it can link specific changes in teachers' instructions with various student outcomes in the classroom. The results revealed that the motive to avoid failure was a positive predictor of worry and a negative predictor of performance. Conversely, the motive to achieve success was a positive predictor of satisfaction during problem-solving, activated pleasant affect, and performance. Furthermore, the results indicate that the assignment of achievement goals can both undermine and enhance satisfaction during problem-solving. In line with earlier studies, it was found that a mastery-focused goal has a more positive effect on satisfaction during problemsolving than does the performance-focused goal. However, the achievement goal conditions effect on pleasant affect and worry were not significant and of the emotional processes during problem-solving only worry significantly mediated the relationship between the motives and performance. Thus, in line with earlier studies (e.g., Bjørnebekk 2009a, b; Bjørnebekk and Gjesme 2009), the results of the present study suggest that for children the achievement motives influence performance more directly.

Several significant Person $\times$ Situation interactions were also revealed. In line with the results of Harackiewicz and her colleagues (Elliot and Harackiewicz 1994; Harackiewicz and Elliot 1993; Senko and Harackiewicz 2005), the results of the present study indicate that mastery emphasis leads to higher satisfaction during problem-solving for those low in the motive to achieve success than a performance emphasis. These results suggest that children low in the motive to approach success enjoy masteryfocused situations more than performance-focused situations when the context is commonly associated with the normal school. The level of worry differs significantly as a 
function of the interaction between individual differences in the motive to avoid failure and achievement goal emphasis. Furthermore, a mastery goal emphasis had the most positive outcome (i.e., reduced worry) for those who were low in fear of failure $\left(M_{\mathrm{f}}\right)$. A possible explanation might be that we used tasks of intermediate difficulty in this study (cf. Fig. 1). According to Atkinson's theory (1964), the motives should be most aroused in these situations. The increased level of activated avoidance motivation $\left(T_{\mathrm{f}}\right)$ may thereby overshadow the effect of achievement goal emphasis for the individuals high in the motive to avoid failure but not for the individuals who are low in it. The strong main effects of the motives on performance and of the motive to achieve success on pleasant affect, in both achievement goal conditions, support this explanation. In sum, it can be assumed that children with high arousability in challenging situations (high $M_{\mathrm{s}}$ or high $M_{\mathrm{f}}$ ) are less likely to adjust their goals, cognitions or feelings in the presence of a stimulus that signals different evaluations of their competence (i.e., mastery vs. performance).

Nevertheless, there are limitations: the achievement goal emphasis was investigated cross-sectionally (between subjects). Thus, there is a need for a longitudinal design to test the proposed causal sequences within subjects. Another limitation of the current study is that there was no performance-avoidance group, but only a mastery and performance group. Furthermore, perhaps the achievement goal manipulation was simply too mild to produce the effects others have found. The approach to measure state test anxiety, satisfaction, and pleasant affect during problem-solving raises issues, however, regarding: causality, since it is possible that how an individual performs on the tasks influences their affects and satisfaction, reversing the direction of the mediational chain (Brodish and Devine 2009, p. 181). Measuring state anxiety, satisfaction, and pleasant affect during the problem-solving session may however contaminate participants' subsequent performance. In the next study, some of these shortcomings are considered.

\section{Study 2}

Method

\section{Participants}

The sample consisted of 331 sixth-graders (11-12-yearolds) from 16 school classes in Oslo. As in study 1, the classes were selected from schools which scored on the same level in the Norwegian national test in mathematics and reading. The average mathematics and reading scores of the sample were 56 and 58, respectively. The participants in the present study scored above average on the nationwide tests. In terms of composition, the sample consisted of 162 boys and 169 girls.

\section{Experimental procedure}

The experiment was carried out in a group-testing session.

Procedure The 16 school classes were randomly assigned to three different experimental conditions, i.e., mastery goal, performance-approach goal, and performance-avoidance goal. Before the experimental procedures were induced, the pupils' motive dispositions were assessed. Each class received the instructions for the condition it was assigned to. Then, pupils received a booklet of problem tasks. The pupils in the two conditions received a test booklet containing identical sets of tasks (40 problems). After the pupils had received the booklets, and after examples of all types of tasks had been illustrated, the specific instruction for the two experimental conditions followed.

The achievement goal manipulation was based on that used by Elliot et al. (2005). Participants in the performance approach and performance-avoidance goals condition were informed, "The purpose of this study is to compare sixth-graders with one another in their ability to solve these problems." In the performance-approach goal condition they were then told that previous work had indicated that most sixth-graders are fairly similar in their ability to solve problems but that some students stand out because they do it exceptionally well. Thus, the problem-solving session would provide the opportunity "to demonstrate that you are an exceptional problem solver." In the performanceavoidance goal condition they were told that previous tests had indicated that most sixth-graders are fairly similar in their ability to solve problems, but that some pupils stand out because they do so poorly. Thus, the session would provide some insight into whether they were a poor problem-solver. Participants in the mastery condition were informed, "The purpose of this study is to collect data on sixth-graders' reactions to the problems." They were additionally told that the session would provide them with the opportunity to "get to know these problems and learn how to solve the problems well." All the pupils were informed that they would receive personal feedback after they completed the task. In the performance-approach condition, they were told that they would be informed "whether you did well compared with others," in the performance-avoidance condition they were told that they would be informed "whether you did poorly compared with others," and in the mastery goal condition they were told that they would be informed "whether you learned how to solve the problems well."

Before starting, pupils were asked to answer some questions about their approach motivation $\left(T_{s}\right)$ and 
avoidance motivation $\left(T_{f}\right)$. They also filled out a questionnaire containing a manipulation check which asked: "What was the goal that you were given for this task?" and they responded with one of the following: "To demonstrate that I am an exceptionally good problem-solver," "To demonstrate that I am not an extremely poor problemsolver," or "To learn how to solve problems." When they had finished, the instructions were repeated.

\section{Measures}

\section{Motives See study 1.}

Approach $\left(T_{s}\right)$ and Avoidance $\left(T_{f}\right)$ motivation To ascertain the amount of approach $\left(T_{\mathrm{s}}\right)$ and avoidance $\left(T_{\mathrm{f}}\right)$ motivation in the achievement situation, a state version of the AMS was used (Bjørnebekk and Gjesme 2009; Gjesme 1983a). In the state version, the items did not focus on situations that are assumed to arouse the same degree of uncertainty as to the possibility of success $\left(P_{\mathrm{s}}\right)$. Instead, they focused on "in this situation," in order to measure different degrees of aroused and manifested achievement motivation $\left(T_{\mathrm{s}}\right.$ and $\left.T_{\mathrm{f}}\right)$. The construction of this scale harmonizes both with achievement motivation theory (cf. Atkinson 1964) and with the principles on which the achievement motives scale was constructed (cf. Nygård and Gjesme 1973). Gjesme's (1983a) empirical study has documented the reliability and validity of using an approach-avoidance motivation questionnaire for middleschool pupils. Approach motivation $\left(T_{\mathrm{s}}\right)$ was assessed using six items from the motive to achieve success $\left(M_{\mathrm{s}}\right)$ section of the achievement motives scale. These items are statements about positive affect: for example, "I am attracted to this situation" and "I find this situation challenging." Avoidance motivation $\left(T_{\mathrm{f}}\right)$ was assessed by employing six items from the motive to avoid failure $\left(M_{\mathrm{f}}\right)$ section of the achievement motives scale. These items deal with negative affect in state form. To illustrate, "I am afraid of failing in this situation" and "I feel anxious about this situation." Participants rated the items on the same four-point scale used with approach motivation. In the present sample, a principal factor analysis with varimax rotation showed that two factors had eigenvalues greater than one (the first three eigenvalues were, respectively, $3.44,3.03$, and 0.88 ). The two-factor solution accounted for $54 \%$ of the total variance. All items loaded satisfactorily on their primary factor (i.e., $>40$ ).

\section{Tasks See study 1.}

Treatment of data We conducted preliminary analyses in which we proportioned the total variance of the dependent variables into within-classes and between-classes components. The ICC was evaluated for our dependent variables (e.g., $T_{\mathrm{s}}, T_{\mathrm{f}}$ and performance). The ICCs were weak and ranged from 0.05 (approach motivation) to 0.08 (performance), indicating that most of the variance was at the individual level. None of the ICC values reached statistical significance. Hence, the data can be analyzed without using multilevel modeling.

A test of orthogonal contrasts tested the effects of the goal conditions: the mastery-performance contrast compared the mastery condition $($ coded +2$)$ with the performance conditions ( -1 each), and the performanceavoidance contrast compared the performance-approach $(+1)$ and the performance-avoidance condition $(-1)$. When the analyses revealed a significant approach-avoidance effect, we ran a new analysis where the approachmastery contrast compared the performance-approach condition $(+1)$ with the mastery condition $(-1)$, and the avoidance-mastery compared the performance-avoidance $(-1)$ and mastery group $(+1)$.

We ran corresponding models to the basic models in study 1: an approach-avoidance interaction model (i.e., $M_{\mathrm{s}} \times$ mastery-performance, $M_{\mathrm{s}} \times$ performance-avoidance, $M_{\mathrm{f}}$ $\times$ mastery-performance, $\quad M_{\mathrm{f}} \times$ performance-avoidance, $M_{\mathrm{s}} \times M_{\mathrm{f}}, \quad M_{\mathrm{s}} \times M_{\mathrm{f}} \times$ mastery-performance, and $M_{\mathrm{s}} \times$ $M_{\mathrm{f}} \times$ approach-avoidance), an avoidance-gender interaction model (i.e., gender $\times$ mastery-performance, gender $\times$ approach-avoidance, $M_{\mathrm{f}} \times$ gender, $M_{\mathrm{f}} \times$ mastery-approach, $M_{\mathrm{f}} \times$ approach-avoidance, $M_{\mathrm{f}} \times$ gender $\times$ mastery-performance and $M_{\mathrm{f}} \times$ gender $\times$ approach-avoidance), and an approach-gender interaction model (i.e., gender $\times$ masteryperformance, gender $\times$ approach-avoidance, $M_{\mathrm{s}} \times$ gender, $M_{\mathrm{s}} \times$ mastery-approach, $M_{\mathrm{s}} \times$ approach-avoidance, $M_{\mathrm{s}} \times$ gender $\times$ mastery-performance, and $M_{\mathrm{s}} \times$ gender $\times$ approach-avoidance) were tested separately.

Manipulation check A chi-square test of independence revealed that goal manipulation was successful, $\chi^{2}$ (4, $N=331)=260.57, \quad p<0.001$. Indeed the pupils' achievement goal reports corresponded to their achievement goal conditions.

\section{Results}

As shown in Table 5, for all measures the Cronbach's alpha levels are acceptable. In addition, it is interesting that the motive to achieve success and approach motivation $\left(T_{\mathrm{s}}\right)$ was positively related to performance, whereas the motive to avoid failure, the achievement goal conditions and avoidance motivation $\left(T_{\mathrm{f}}\right)$ were negatively correlated with total performance. 
Table 5 Descriptive statistics, reliabilities, and intercorrelations among the variables in study 2

\begin{tabular}{|c|c|c|c|c|c|c|c|c|c|c|}
\hline$N=331$ & M & $\mathrm{SD}$ & $\alpha$ & 1 & 2 & 3 & 4 & 5 & 6 & 7 \\
\hline 1. Gender & - & - & - & 1 & & & & & & \\
\hline 2. Motive to achieve success & 44.5 & 6.7 & 0.85 & -0.01 & 1 & & & & & \\
\hline 3. Motive to avoid failure & 29.9 & 8.5 & 0.89 & -0.01 & $-0.24 * *$ & 1 & & & & \\
\hline 4. Achievement goal condition & - & - & - & 0.09 & 0.07 & -0.07 & 1 & & & \\
\hline 5. Approach motivation & 16.7 & 3.7 & 0.81 & -0.07 & $0.55 * *$ & $-0.12 *$ & 0.05 & 1 & & \\
\hline 6. Avoidance motivation & 10.7 & 3.7 & 0.80 & 0.02 & $-0.16 * *$ & $0.58 * *$ & 0.02 & -0.04 & 1 & \\
\hline 7. Performance & 23.2 & 8.9 & 0.88 & -0.01 & $0.26 * *$ & $-0.15 * *$ & $-0.17 * *$ & $0.22 * *$ & $-0.17 * *$ & 1 \\
\hline
\end{tabular}

$* p<0.05 ; * * p<0.01$ (two-tailed)

\section{Approach motivation $\left(T_{s}\right)$}

Regressing $\mathrm{T}_{\mathrm{s}}$ on the proposed antecedents yielded a significant effect for the overall approach-avoidance interaction model, $F_{12}, 318=14.57, \quad p<0.0001, R^{2}=0.36$. Gender was shown to be unrelated to Ts. In the second step, the achievement motives made a significant contribution, $F_{2,327}=70.52, p<0.001, R^{2}=0.30$. Only $M_{\mathrm{s}}, \beta=0.55$, $t_{1,327}=11.61, p<0.001$, yielded a significant unique contribution, however. In the third step, the goal conditions made a marginally significant contribution, $F_{2,325}=2.37$, $p<0.10, R^{2}=0.01$. Performance-approach goal participants scored higher on approach motivation (Ts) than the performance-avoidance participants, $\beta=0.08, t_{1}, 325=$ $1.70, p<0.10$. There was no significant difference between the performance and mastery participants. In terms of interactions, the two-way interaction between $M_{\mathrm{s}}$ and $M_{\mathrm{f}}$ made only a marginally significant contribution, $F_{1,324}=$ 2.77, $p<0.10, R^{2}=0.006$. More importantly, the twoway interactions $M_{\mathrm{s}} \times$ mastery-performance (Fig. 3a), $F_{1}, \quad 325=5.78, \quad p<0.05, \quad R^{2}=0.012, \quad M_{\mathrm{f}} \times$ masteryperformance (Fig. 3b), $F_{1}, 325=4.95, p<0.05, R^{2}=$ $0.010, M_{\mathrm{f}} \times$ approach-avoidance (Fig. $3 \mathrm{c}$ ), $F_{1,325}=5.16$, $p<0.05, R^{2}=0.011$, were significant as well. The $M_{\mathrm{s}}, M_{\mathrm{f}}$, and mastery-performance interactions were qualified by the marginally significant $M_{\mathrm{s}} \times M_{\mathrm{f}} \times$ mastery-performance, $F_{1,322}=2.86, p<0.10, R^{2}=0.007$. The approach motivation $\left(T_{\mathrm{s}}\right)$ of success-oriented pupils (high $M_{\mathrm{s}}-$ low $\left.M_{\mathrm{f}}\right)$ is highest, whereas the approach motivation of the failureoriented pupils (low $M_{\mathrm{s}}$ high $M_{\mathrm{f}}$ ) is lowest under the mastery goal condition. Moreover, as depicted in Fig. 3c, pupils high in $M_{\mathrm{f}}$ decreased their $T_{\mathrm{s}}$ in the performance-avoidance condition, but not in the performance-avoidance condition.

Gender, as both main and interaction effects, revealed few clear-cut significant results and explained variances of less than $1 \%$ of total variance on all three dependent variables. In Fig. 5c, however, we have illustrated a tendency of gender differences in performance as a function of motives and achievement goal conditions.

\section{Avoidance motivation $\left(T_{f}\right)$}

Regressing $T_{\mathrm{f}}$ on the proposed antecedents yielded a significant effect for the overall approach-avoidance interaction model, $F_{12}, 318=15.74, p<0.0001, R^{2}=0.37$. In the first step, gender was unrelated to avoidance motivation, whereas the motives accounted for an additional proportion of variance in the second step, $F_{2,327}=81.10$, $p<0.0001, R^{2}$ change $=0.33$. Only $M_{\mathrm{f}}, \quad \beta=0.57$, $t_{1,327}=12.26, p<0.001$, however, yielded a significant unique contribution. In the second step, there was a marginally significant difference between the mastery and the performance goal participants. Performance goal participants scored higher on avoidance motivation $\left(T_{\mathrm{f}}\right)$ than the mastery participants, $\beta=-0.08, t_{1}, \quad 325=-1.68$, $p<0.10$. In terms of interactions, both the two-ways
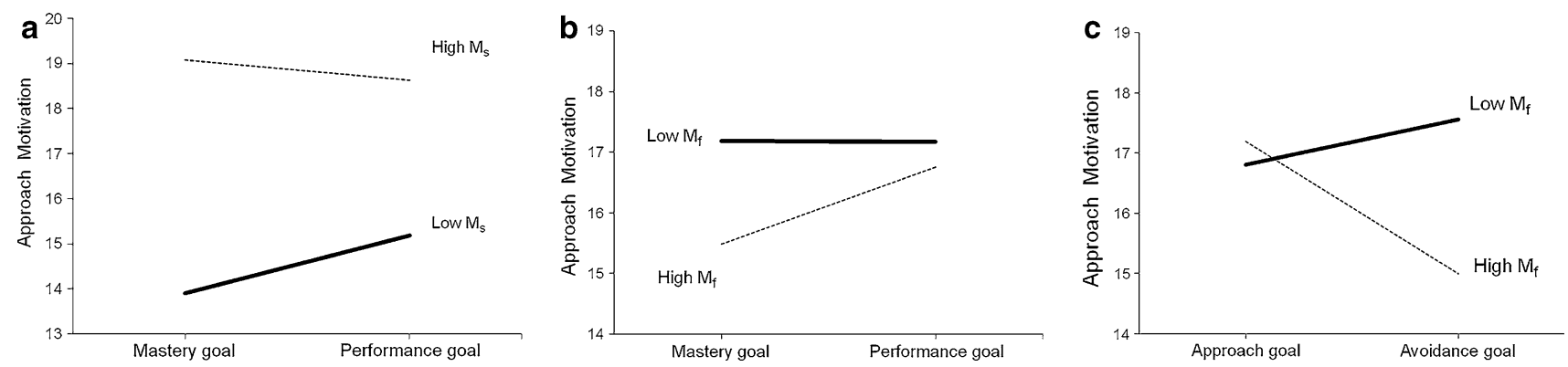

Fig. 3 Approach motivation $\left(T_{\mathrm{s}}\right)$ as a function of combinations of the motive to approach success $\left(M_{\mathrm{s}}\right)$, the motive to avoid failure $\left(M_{\mathrm{f}}\right)$, and the mastery, performance-approach, and performance-avoidance goal conditions 
Fig. 4 Avoidance motivation as a function of combinations of the motive to approach success $\left(M_{\mathrm{s}}\right)$, the motive to avoid failure $\left(M_{\mathrm{f}}\right)$, and the achievement goal conditions
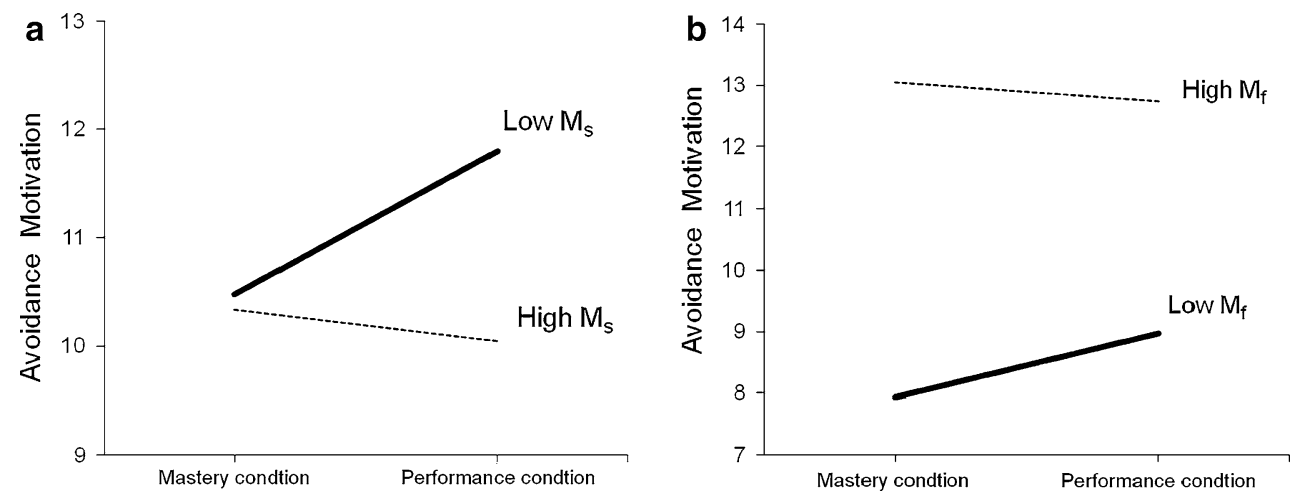

between $M_{\mathrm{s}}$ and mastery-performance goals (Fig. 4a), $F_{1,327}=3.60, p<0.05, R^{2}=0.011$, and $M_{\mathrm{f}}$ and masteryperformance goals (Fig. $4 \mathrm{~b}$ ), $F_{1,327}=3.70, \quad p<0.05$, $R^{2}=0.008$, yielded a significant effect on $T_{\mathrm{f}}$. The interaction between $M_{\mathrm{f}}$ and approach-avoidance goals was marginally significant, $F_{1,327}=3.02, \quad p<0.10, \quad R^{2}=$ 0.006. Finally, there was a significant $M_{\mathrm{f}} \times$ gender $\times$ approach-avoidance interaction, $F_{1,323}=3.87, p<0.05$, $R^{2}=0.01$, indicating that the avoidance motivation of girls high in $M_{\mathrm{f}}$ lowers their avoidance motivation $\left(T_{\mathrm{f}}\right)$ from the performance-approach to the performanceavoidance condition. For boys, $T_{\mathrm{f}}$ remained about the same.

\section{Performance}

Regressing total performance on the proposed antecedents yielded a significant effect for the overall approachavoidance interaction model, $F_{12,314}=5.67, p<0.0001$, $R^{2}=0.18$. Gender was shown to be unrelated to performance. In the second step, the achievement motives made a significant contribution, $F_{2,327}=13.47, p<0.001, R^{2}=$ 0.08 . $M_{\mathrm{s}}$ was positively related to performance, $\beta=0.25$, $t_{1,327}=4.35, p<0.001$, and $M_{\mathrm{f}}$ was negatively related, $\beta=-0.10, t_{1,327}=-1.75, p<0.10$. In the third step, the goal conditions made a significant contribution,
$F_{2,321}=6.89, p<0.001, R^{2}=0.04$. Mastery goal participants performed better than the performance goal participants, $\beta=0.19, t_{1,325}=3.63, p<0.001$. There was no significant difference between the approach and avoidance participants. In terms of interactions, the two-way interactions $M_{\mathrm{s}} \times$ mastery-performance, $F_{1,320}=7.48$, $p<0.001, \quad R^{2}=0.02, \quad M_{\mathrm{f}} \times$ mastery-performance, $F_{1,320}=10.27, p<0.001, R^{2}=0.028$, and gender $\times M_{\mathrm{f}}$, $F_{1,320}=12.11, p<0.001, R^{2}=0.032$, were significant. The former indicated that pupils high in $M_{\mathrm{s}}$ (Fig. 5a) and low in $M_{\mathrm{f}}$ (Fig. 5b) performed significantly better under the mastery condition compared with the performance conditions. The latter indicated that anxiety $\left(M_{\mathrm{f}}\right)$ only influenced boys negatively (Fig. 5c). Moreover, the three-way interaction $M_{\mathrm{s}} \times M_{\mathrm{f}} \times$ approach-avoidance (Fig. 6), $F_{1,317}=$ $6.69, p<0.01, R^{2}=0.018$, indicated that pupils with high anxiety $\left(M_{\mathrm{f}}\right)$ can perform well in performance approach conditions, but only if they also score high on the motive to achieve success $\left(M_{\mathrm{s}}\right)$.

\section{Mediational analysis}

To reveal whether approach motivation mediates the motive to achieve success-performance linkage and
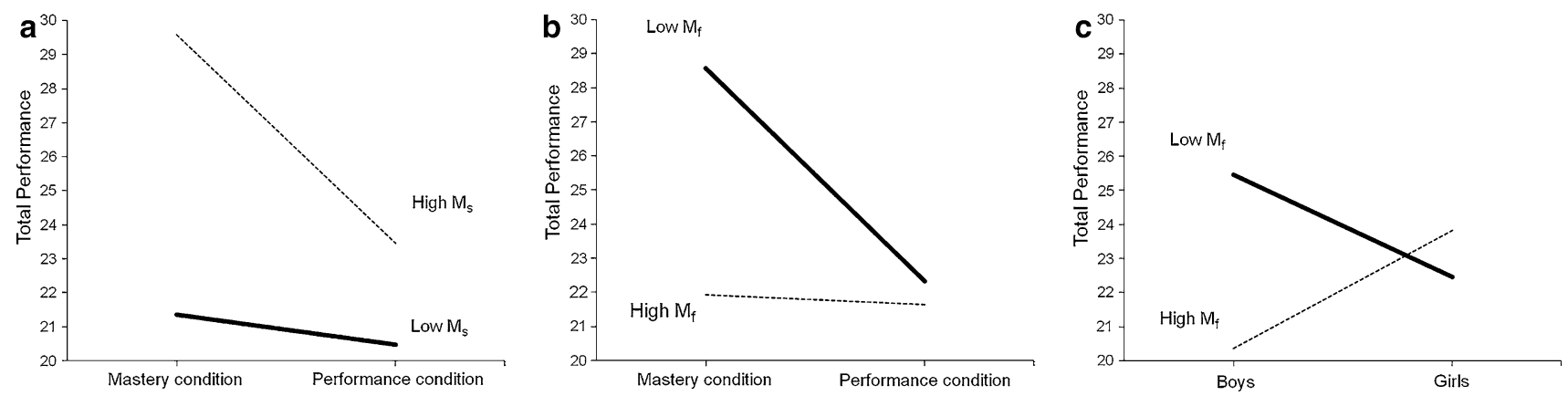

Fig. 5 Performance as a function of combinations of the motive to approach success $\left(M_{\mathrm{s}}\right)$, the motive to avoid failure $\left(M_{\mathrm{f}}\right)$, the masteryperformance goal conditions, and as a function of gender (c) 
Fig. 6 Performance as a function of combinations of the motive to avoid failure $\left(M_{\mathrm{f}}\right)$, the motive to approach success $\left(M_{\mathrm{s}}\right)$, and the approachavoidance goal conditions

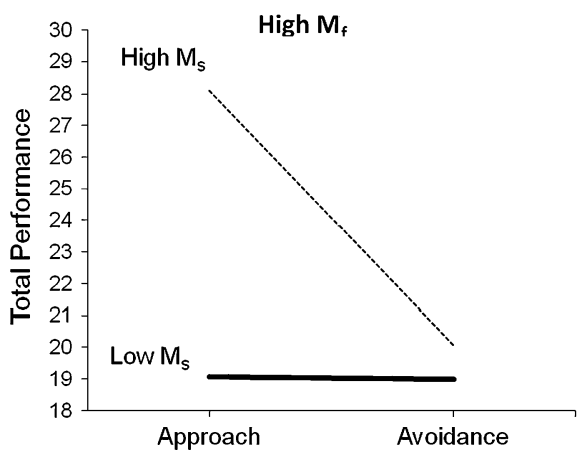

avoidance motivation mediates the motive to avoid failureperformance linkage, several stages of analysis are necessary. First, the predictor-criterion correlation must be significant. The preceding analysis satisfied this requirement by establishing a positive relationship between the motive to achieve success and performance, as well as a negative relationship between the motive to avoid failure and performance. Second, a relationship between the predictor variable and the hypothesized mediator must be established to document the first link in the mediational chain. As we can see in Table 5, the correlations between the motive to approach success and approach motivation and between the motive to avoid failure and avoidance motivation are both significant. Third, to complete the mediational chain, a relationship between the mediator and the outcome variable must be established while controlling for the predictor variable, and the direct relationship between the predictor variable and the outcome measure should be reduced. To test the final link, we conducted a series of analyses in which performance was regressed on the motives with approach/avoidance motivation also in the equation. The approach motivation mediational analyses revealed one significant relationship for approach motivation. The beta coefficient for the direct relationship between the motive to approach success and performance dropped from 0.26 to 0.19 in this analysis. The utilization of Sobel's procedure (1982) for testing the significance of indirect, mediational relationships substantiated a marginally significant partial mediation effect of approach motivation on the relationship between the motive to approach success and performance $(z=-1.77, p=0.07)$. The avoidance motivation mediational analyses revealed one significant relationship for avoidance motivation, indicating that pupils with high levels of avoidance motivation performed worse. The direct effect for the motive to avoid failure no longer attained significance with avoidance motivation in the equation, and the decrease in the beta coefficient for this effect (from -0.15 to -0.08 ) provides evidence that avoidance motivation mediated the direct effect of the motive to avoid failure on performance $(z=-2.11$, $p<0.05)$.
Discussion and summary

In study 2, our aim was to extend the two achievement goal conditions with a performance-avoidance condition and additionally to investigate important antecedents and consequences of approach motivation $\left(T_{\mathrm{s}}\right)$ and avoidance motivation $\left(T_{\mathrm{f}}\right)$ on performance, including possible effects of gender. The motive to achieve success $\left(M_{\mathrm{s}}\right)$ and the motive to avoid failure $\left(M_{\mathrm{f}}\right)$ played a major role regarding approach $\left(T_{\mathrm{s}}\right)$ and avoidance motivation $\left(T_{\mathrm{f}}\right)$, respectively. As far as performance is concerned, the most important single factors were $M_{\mathrm{s}}$ and the mastery-goal situation.

The performance-approach participants scored higher on approach motivation $\left(T_{\mathrm{s}}\right)$ than the performance-avoidance participants. No significant difference in $T_{\mathrm{s}}$ between performance and mastery participants was observed. Regarding avoidance motivation $\left(T_{\mathrm{f}}\right)$, pupils low in $M_{\mathrm{s}}$ increased their $T_{\mathrm{f}}$-scores from the mastery- to the performance goal conditions. As far as performance was concerned, pupils high in $M_{\mathrm{s}}$ performed significantly better under the mastery condition than the performance conditions. It was also noted from Fig. 6 that pupils high in both $M_{\mathrm{s}}$ and $M_{\mathrm{f}}$ ("the perfectionists") had a significantly higher performance in the performance-approach condition compared with the performance-avoidance condition. Furthermore, it was seen that the performance-avoidance goal condition reduced both high $M_{\mathrm{f}}$ girls' and high $M_{\mathrm{f}}$ boys' performance. Conversely, the performance scores for the pupils high in $M_{\mathrm{s}} /$ low in $M_{\mathrm{f}}$ (Fig. 6) increased in the performance-avoidance condition compared with the performance-approach condition. Hence, an avoidance-goal situation might be good for some pupils' performance. In general, however, an avoidance-goal situation seems to accentuate the negative effects of a high avoidance motive $\left(M_{\mathrm{f}}\right)$ on performance. Moreover, in experiment 2 avoidance motivation was validated as a mediator of the relationship between the motive to avoid failure and performance. Finally, the highest performance was found among boys with low $M_{\mathrm{f}}$ in the mastery situation. In sum, it is important to highlight that motivation in achievement settings is complex and achievement goals are only one of several 
types of operative variable. In particular, the individuals' motive dispositions (i.e., $M_{\mathrm{s}}$ and $M_{\mathrm{f}}$ ) seem to play a major role in the motivational processes and in the outcomes (e.g., performance). Nevertheless, there is a limitation: there is a need for a longitudinal design to test the proposed causal sequences within subjects.

Open Access This article is distributed under the terms of the Creative Commons Attribution Noncommercial License which permits any noncommercial use, distribution, and reproduction in any medium, provided the original author(s) and source are credited.

\section{References}

Aiken, L. S., \& West, S. G. (1991). Multiple regression: Testing and interpreting interactions. Newbury Park, CA: Sage.

Ames, C. (1984). Achievement attribution and self-instruction under competitive and individualistic goal structures. Journal of Educational Psychology, 76, 478-487.

Ames, C. (1992). Classrooms: Goals, structures, and student motivation. Journal of Educational Psychology, 84(3), 261-271.

Ames, C., \& Archer, J. (1988). Achievement goals in the classroom: Students' learning strategies and motivation processes. Journal of Educational Psychology, 80(3), 260-267.

Atkinson, J. W. (1957). Motivational determinants of risk-taking behavior. Psychological Review, 64, 359-372.

Atkinson, J. W. (1964). Introduction to motivation. New York, NY: Van Nostrand.

Atkinson, J. W., \& Litwin, G. H. (1960). Achievement motive and test anxiety conceived as motive to approach success and motive to avoid failure. Journal of Abnormal and Social Psychology, 60, $52-63$.

Barron, K. E., \& Harackiewicz, J. M. (2001). Achievement goals and optimal motivation: Testing multiple goal models. Journal of Personality and Social Psychology, 80(5), 706-722.

Bjørnebekk, G. (2007). Reinforcement sensitivity theory and major motivational and self- regulatory processes in children. Personality and Individual Differences, 43, 1980-1990.

Bjørnebekk, G. (2008a). Motivation and distance to goal time: Their effect on cognitive and affective manifestations. Unpublished doctoral dissertation, University of Oslo, Norway.

Bjørnebekk, G. (2008b). Positive and negative affect as modulators of cognition and motivation: The rediscovery of affect in achievement theory. Scandinavian Journal of Educational Research, 52, 153-170.

Bjørnebekk, G. (2009a). Mediators and moderators of approachperformance and avoidance- performance relationships in children: Theoretical and experimental aspects. In S. A. Karabenick, P. Nenninger, A. Efklides, \& M. Wosnitza (Eds.), Contemporary motivation research: From global to local perspectives (pp. 185-205). Göttingen: Hogrefe \& Huber.

Bjørnebekk, G. (2009b). Psychometric properties of the scores on the behavioral inhibition and activation scales in a sample of Norwegian children. Educational and Psychological Measurement, 69, 636-654.

Bjørnebekk, G., \& Diseth, Å. (2010). Approach and avoidance temperaments and achievement goals among children. Personality and Individual Differences, 49, 938-943.

Bjørnebekk, G., \& Gjesme, T. (2009). Motivation and temporal distance: Effect on cognitive and affective manifestations. Psychological Reports, 105, 339-360.

Brodish, A. B., \& Devine, P. G. (2009). The role of performanceavoidance goals and worry in mediating the relationship between stereotype threat and performance. Journal of Experimental Social Psychology, 45, 180-185.

Christophersen, K.-A., \& Rand, P. (1982). Factor structure of the achievement motives scale (AMS): Two factors-two samples. Scandinavian Journal of Educational Research, 26, 13-28.

Cock, D., \& Halvari, H. (2001). Motivation, performance and satisfaction at school. The significance of the achievement motives-autonomy interaction. In A. Efklides, J. Kuhl, \& R. Sorrentino (Eds.), Trends and prospects in motivation research (pp. 65-84). The Netherlands: Kluwer Academic Publishers.

Durik, A. M., \& Harackiewicz, J. M. (2003). Achievement goals and achievement motivation: Coherence, concordance, and achievement orientation. Journal of Experimental Social Psychology, 39, 378-385.

Dweck, C. S. (1986). Motivational processes affecting learning. American Psychologist, 41, 1040-1048.

Dweck, C. S., \& Leggett, E. L. (1988). A social-cognitive approach to motivation and personality. Psychological Review, 95(2), 256-273.

Elliot, A. J. (1997). Integrating the "classic" and the "contemporary" approaches to achievement motivation: A hierarchal model of approach and avoidance achievement motivation. In M. L. Maehr \& P. J. Pintrich (Eds.), Advances in motivation and achievement (Vol. 10, pp. 143-180). Greenwich, CT: JAI Press.

Elliot, A. J. (1999). Approach and avoidance motivation and achievement goals. Educational Psychologist, 34, 169-189.

Elliot, A. J. (2006). The hierarchical model of approach-avoidance motivation. Motivation and Emotion, 30, 111-116.

Elliot, A. J., \& Church, M. A. (1997). A hierarchical model of approach and avoidance achievement motivation. Journal of Personality and Social Psychology, 72, 218-232.

Elliot, A. J., \& Harackiewicz, J. M. (1994). Goal setting, achievement orientation, and intrinsic motivation: A mediational analysis. Journal of Personality and Social Psychology, 66(5), 968-980.

Elliot, A. J., \& Harackiewicz, J. M. (1996). Approach and avoidance achievement goals and intrinsic motivation: A mediational analysis. Journal of Personality and Social Psychology, 70(3), 461-475.

Elliot, A. J., \& McGregor, H. A. (1999). Test anxiety and the hierarchical model of approach and avoidance motivation. Journal of Personality and Social Psychology, 76, 628-644.

Elliot, A. J., \& McGregor, H. A. (2001). A $2 \times 2$ achievement goal framework. Journal of Personality and Social Psychology, 80, 501-519.

Elliot, A. J., Shell, M. M., Henry, K., \& Maier, M. A. (2005). Achievement goals, performance contingencies, and performance attainment: An experimental test. Journal of Educational Psychology, 97, 630-640.

Elliott, E. S., \& Dweck, C. S. (1988). Goals: An approach to motivation and achievement. Journal of Personality and Social Psychology, 54, 5-12.

Gjesme, T. (1974). Goal distance in time and its effects on the relation between achievement motives and performance. Journal of Research in Personality, 8, 161-171.

Gjesme, T. (1983a). Motivation to approach success (Ts) and motivation to avoid failure (Tf). Scandinavian Journal of Educational Research, 27, 145-164.

Gjesme, T. (1983b). Worry and emotionality components of test anxiety in relation to situational and personality determinants. Psychological Reports, 52, 267-280.

Gjesme, T., \& Nygård, R. (1970). Achievement-related motives: Theoretical considerations and construction of a measuring instrument. Unpublished report, University of Oslo.

Halvari, H. (1997). Moderator effects of age on the relation between achievement motives and performance. Journal of Research in Personality, 31, 303-318. 
Harackiewicz, J. M., \& Elliot, A. J. (1993). Achievement goals and intrinsic motivation. Journal of Personality and Social Psychology, 65, 904-915.

Hyde, J. S. (2005). The gender similarities hypothesis. American Psychologist, 60, 581-592.

Krull, J. L., \& MacKinnon, D. P. (1999). Multilevel mediation modeling in group-based intervention studies. Evaluation Review, 23, 418-444.

Krull, J. L., \& MacKinnon, D. P. (2001). Multilevel modeling of individual and group level mediated effects. Multivariate Behavioral Research, 36, 249-277.

Kuhl, J. (1982). The expectancy-value approach within the theory of social motivation: Elaborations, extensions, critique. In $\mathrm{N}$. T. Feather (Ed.), Expectations and actions: Expectancy-value models in psychology (pp. 125-171). Hillsdale, NJ: Erlbaum.

Kuhl, J. (1994). A theory of action versus state orientation. In J. Kuhl \& J. Beckman (Eds.), Volition and personality: Action versus state orientation (pp. 9-46). Göttingen, Germany: Hogrefe \& Huber.

Linnenbrink, E. A. (2004). Person and context: Theoretical and practical concerns in achievement goal theory. In P. R. Pintrich \& M. L. Maehr (Eds.), Motivating students, improving schools: The legacy of Carol Midgley. Advances in motivation and achievement (Vol. 13, pp. 159-185). San Diego, CA: Elsevier Academic Press.

Maehr, M. L. (1984). Meaning and motivation: Toward a theory of personal investment. In R. Ames \& C. Ames (Eds.), Research on motivation in education. Student motivation (Vol. 1, pp. 115-144). NY: Academic Press.

Maehr, M. L., \& Midgley, C. (1991). Enhancing student motivation: A schoolwide approach. Educational Psychologist, 26, 399-427.

McClelland, D. C. (1955). Notes for revised theory of motivation. In D. C. McClelland (Ed.), Studies in motivation (pp. 226-234). New York, NY: Appleton-Century-Crofts.

Nicholls, J. G. (1989). The competitive ethos and democratic education. Cambridge, MA: Harvard University Press.

Nolan, S. (1988). Reasons for studying. Motivational orientation and study strategies. Cognition and Instruction, 5, 269-287.

Nygård, R. (1975). A reconsideration of the achievement motivation theory. European Journal of Social Psychology, 5, 61-92.

Nygård, R., \& Gjesme, T. (1973). Assessment of achievement motives: Comments and suggestions. Scandinavian Journal of Education Research, 17, 39-46.

Pintrich, P. R. (2000). The role of goal orientation in self-regulated learning. In M. Boekaerts, P. R. Pintrich, \& M. Zeidner (Eds.), Handbook of self-regulation (pp. 451-502). San Diego, CA: Academic Press.

Puca, R. M., \& Schmalt, H.-D. (1999). Task enjoyment: A mediator between achievement motives and performance. Motivation and Emotion, 23, 15-29.
Raudenbush, S. W., \& Bryk, A. S. (2002). Hierarchical linear models: Applications and data analysis methods. CA: Sage Publications.

Raynor, J. O. (1974). Relationships between achievement-related motives, future orientation, and academic performance. In J. W. Atkinson \& J. O. Raynor (Eds.), Motivation and achievement. Washington DC: Winston \& Sons.

Roeser, R., Midgley, C., \& Urdan, T. (1996). Perceptions of the school psychological environment and adolescents' psychological and behavioral functioning in school. Journal of Educational Psychology, 88, 408-422.

Sarason, S. B., Davidson, K. S., Lighthall, F. F., \& Waite, R. R. (1958). A test anxiety scale for children. Child Development, 29, $105-113$.

Senko, C., \& Harackiewicz, J. M. (2005). Achievement goals, task performance, and interest: Why perceived goal difficulty matters. Personality and Social Psychology Bulletin, 31, 1739-1753.

Singer, J. D., \& Willett, J. B. (2003). Applied longitudinal data analysis: Modeling change and event occurrence. New York, NY: Oxford University Press.

Sobel, M. E. (1982). Asymptotic confidence intervals for indirect effects in structural equation models. In S. Leinhardt (Ed.), Sociological methodology 1982 (pp. 290-312). Washington DC: American Sociological Association.

Spielberger, C. D. (1973). Preliminary manual for the state-trait anxiety inventory for children (how i feel questionnaire). Palo Alto, CA: Consulting Psychologist Press.

Thrash, T. M., Elliot, A. J., \& Schultheiss, O. C. (2007). Methodological and dispositional predictors of congruence between implicit and explicit need for achievement. Personality and Social Psychology Bulletin, 33, 961-974.

Tyson, D. F., Linnenbrink-Garcia, L., \& Hill, N. E. (2009). Regulating debilitating emotions in the context of performance: Achievement goal orientations, achievement-elicited emotions, and socialization contexts. Human Development, 52, 329-356.

Updegraff, J. A., Gable, S. L., \& Taylor, S. E. (2004). What makes experiences satisfying? The interaction of approach- avoidance motivations and emotions in well-being. Journal of Personality and Social Psychology, 86, 496-504.

Urdan, T., \& Turner, J. C. (2005). Competence motivation in the classroom. In A. J. Elliot \& C. S. Dweck (Eds.), Handbook of competence and motivation (pp. 297-317). New York, NY: Guilford.

Yik, M. S., Russell, J. A., \& Feldman Barrett, L. (1999). Structure of the self-reported current affect: Integration and beyond. Journal of Personality and Social Psychology, 77, 600-619. 